\title{
CORRECTION OF FALSE MOVES IN PURSUIT TRACKING
}

\author{
RONALD W. ANGEL ${ }^{1}$ AND JOSEPH R. HIGGINS ? \\ School of Medicine, Stanjord University
}

\begin{abstract}
Ten $S$ s were tested on a pursuit tracking test under display conditions that caused them to make false moves. The mean latency of the false moves was longer than the mean latency of correct moves. The mean time needed to arrest false moves was less than the mean time needed to initiate any motor response, whether correct or incorrect. Forty-one percent of the false moves were arrested in less than the estimated minimum time needed to process visual feedback. The data confirm previous reports that $S_{\mathrm{s}}$ are able to correct errors more quickly than they can respond to external stimuli.
\end{abstract}

Several experiments have shown that when two stimuli are separated by an interval of $.5 \mathrm{sec}$. or less, the latency of the second response is longer than that of the first. In order to explain this finding, Welford (1952) has suggested that sensory feedback from the first response may "capture" the central mechanisms for a brief period and thereby delay the processing of a second stimulus. More recently, however, Gibbs (1965) has found that incorrect motor responses can be amended within $.1 \mathrm{sec}$. from the time they begin. This observation shows that feedback from one movement does not necessarily increase the latency of a succeeding response. On the contrary, Gibbs inferred that the rapid corrective responses were facilitated by proprioceptive feedback from the incorrect moves. The experiments reported in the present paper confirm the work of Gibbs.

Method.-Five men and five women, of ages ranging from 18 to 45 , used a joy stick to position a cursor line on an oscilloscope and track a target line. Hand movement to the right or left was detected by means of a potentiometer and a tachometer, which were coupled to the joy stick. Voltages proportional to position and velocity of the hand were recorded on magnetic tape along with a signal showing position of the target line. The tape-recorded signals were displayed by means of a strip-chart recorder, and measurements were made on the paper (see Fig. 1 and 2 ).

The position of the target line was controlled by $E$, who operated a hand switch, causing the target to occupy one of three positions: the center of the display tube, $3 \mathrm{~cm}$. to the right, or $3 \mathrm{~cm}$. to the left. The track consisted of 140 target steps, which appeared random but actually followed the same order for every $S$. When the target was centered, it jumped to the right or left with equal probability, and each lateral jump was followed by a return to center. Every block of 20 steps contained 5 jumps to the right, 5 to the left, and 10 back to center.

A second switch, also operated by $E$, determined

Also at Veterans Administration Hospital, Neurophysiology Laboratory.

Requests for reprints should be sent to Ronald W. Angel, Veterans Administratlon Hospital, 3801 Junipero Serra Boulevard Palo Alto, California 94304 .

2 The authors wish to thank Byron W. Brown, Jr., for belp with the statistical analysis and Norman $f$. Mackworth for helpful suggestions. the directional relation between control and display. When this switch was in the "positive" position, the joy stick and the display cursor moved in the same direction. When the switch was in the "negative" position, the joy stick and the display cursor moved in opposite directions. On the first 40 target steps, the control-display relation was positive. On Steps $41-80$, the relation was negative. For Steps $81-120$, the relation was changed after each block of 10 moves, as illustrated in Fig. 3. For the final 20 steps, the control-display relation was changed after every recentering move.

The $E$, who was seated behind $S$, monitored the display tube and made sure that the display cursor was superimposed on the target before switching the target line to a new position. Since the different $S$ s required variable times to complete their moves, it was not feasible to standardize the interval between the completion of one response and the time of the next target step. In view of the fact that temporal uncertainty affects reaction time, the intervals between successive target steps were recorded

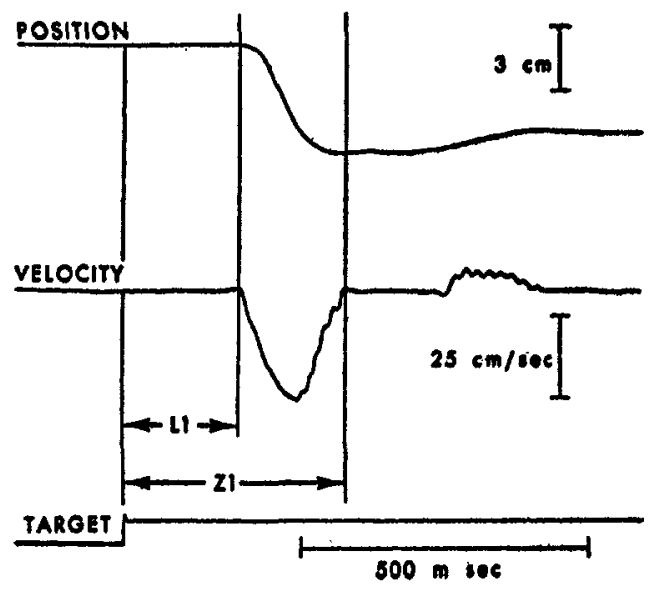

F10. 1. Tracking response with incompatible control-display relation. (Top line: position of joy stick. Second line: velocity. Downward deflections indicate move to right. As trace begins, velocity is zero. At the time shown by step on lower line, target Jumps $3 \mathrm{~cm}$. toward the lelt. After a latency of 200 msec. [L1], joy stick begins to move to the right. Velocity returns to zero level $380 \mathrm{msec}$ after target step [Z1]. Duration of the initial move is 180 msec. [Z1 minus L1].) 


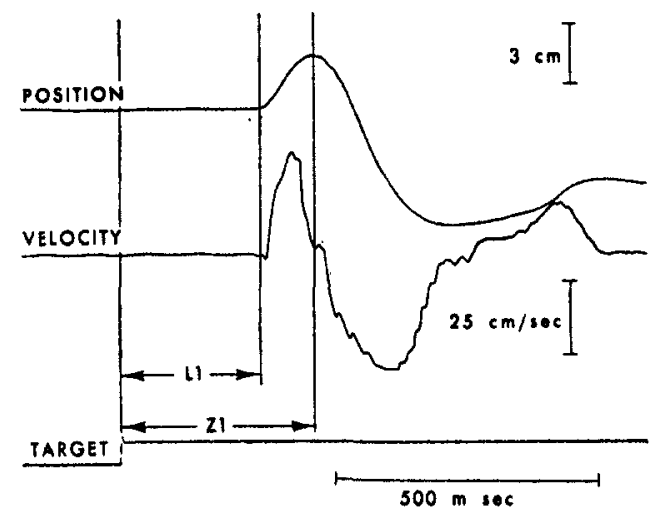

FIG. 2. Incorrect tracking response. (Step on bottom line shows time when target jumps $3 \mathrm{~cm}$. to left. After a latent period of 267 msec. [L1], joy stick begins to move leftward and the response marker [not shown] moves rightward, adding to the error generated by track. The false move is arrested at time $\mathrm{Z1}, 367 \mathrm{msec}$. after target step. Duration of false move is 100 msec. [Z1 minus L1].)

and measured along with the other data. The interstep intervals were found to range between 2 and $4 \mathrm{sec}$, but the variance was approximately the same for different $S \mathrm{~s}$ and different parts of the track. Hence none of the effects reported can be ascribed to differences of temporal uncertainty.

Results and discussion.-Each of the $10 \mathrm{Ss}$ made 140 moves, so that 1,400 moves were recorded alto- gether. Of this total, 141 were found to be false moves (FMs), defined as moves in which the initial acceleration caused the response marker to move away from the target. The number of FMs varied from 6 to 21 per $S$, the group mean of 14.1 being very close to $10 \%$ of the total series. The errors were not distributed randomly throughout the track, but tended to occur when the polarity of the control-display relation was negative (see Fig, 3). This agrees with Gibbs' (1965) finding that the frequency of errors was much greater when the incompatible display was used.

In order to determine the mean reaction times (RTs) for correct moves (CMs), measurements were taken from all correct responses made on Steps 71-80, which were selected to represent optimal performance with the negative display polarity. The mean RTs ranged from 237 to 364 msec., the group mean being $300 \mathrm{msec}$. The mean RTs for FMs ranged from 245 to $480 \mathrm{msec}$, the group mean being $357 \mathrm{msec}$. The difference of the group means for CMs and FMs was significant, $t(9)=3.2, p<.01$. This result agrees with Gibbs' (1965) finding that on probable and unequivocal steps, the errors were associated with longer latencies, i.e., the opposite of the expected relation between accuracy and speed.

The duration of any move was defined as the time from onset of movement to the time when velocity became zero (see Fig. 1 and 2). The mean

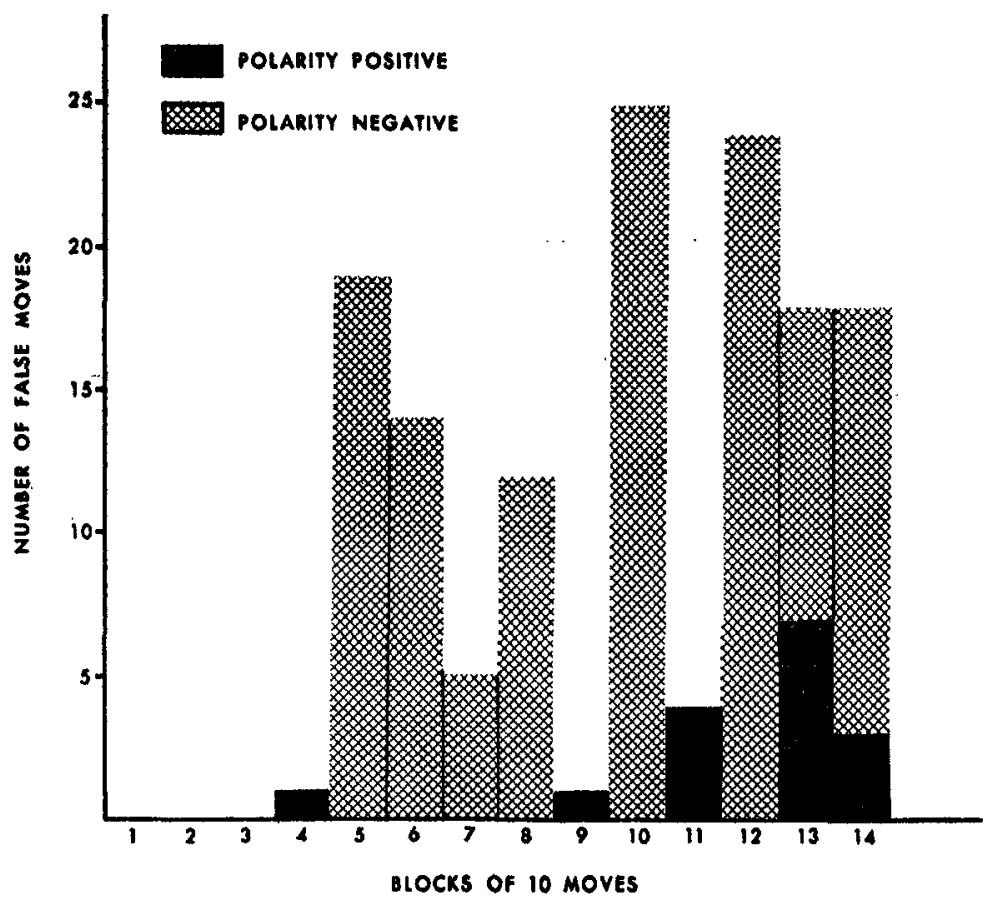

Fig. 3. Numbers of false moves occurring in different portions of the tracking task. (The probability of obtaining a false move depends on the polarity of the feedback display, The moves in Blocks 1-4, 9 , and 11 were made under normal display conditions, and relatively few false moves occurred. The moves in Blocks $5-8,10$, and 12 were made with the incompatible display, and many false moves were obtained. In Blocks 13 and 14, the polarity of the display was changed after each pair of target steps,) 
duration of the CMs in response to Target Steps $71-80$ varied from 168 to 571 msec., the group mean being $362 \mathrm{msec}$. The mean duration of FMs varied from 156 to $276 \mathrm{msec}$, the group mean being 215 msec. This is $147 \mathrm{msec}$. less than the mean for CMs, $t(9)=4.5, p<.005$.

If $S$ s can amend their own FMs within so short a time, are the corrective responses based on visual feedback from the display? Keele and Posner (1968) have found that the minimum amount of time necessary to process visual feedback from a movement is $190-260 \mathrm{msec}$. In the present experiments, the group mean for amendment times was $215 \mathrm{msec}$, but for three $S$ s the mean amendment times were less than $190 \mathrm{msec}$. Moreover, $41 \%$ of all FMs made by the $10 \mathrm{Ss}$ were arrested within less than $190 \mathrm{msec}$.

If some FMs are arrested before any visual feedback could become effective, what provides the stimulus for the very fast corrective responses? Gibbs (1965) postulated that $S$ s use proprioceptive monitoring to provide the fast correction times. An alternative possibility is that the brain monitors and records outgoing motor impulses, amending those which do not agree with the intended plan of action.

The findings confirm the work of Gibbs (1965) and also agree with Rabbitt's (1966) conclusion that error correcting responses are faster than equivalent, correct responses. It appears that $S \mathrm{~s}^{\prime}$ internal monitoring of their own responses may allow them to correct errors more quickly than they respond to any external signal from the display. No evidence was found to support the view that proprioceptive feedback delays the response to stimuli arriving during movement.

\section{REFERENCES}

Grbes, C, B. Probability learning in step-input tracking. British Journal of Psychology, 1965, 56, 233-242.

KEEIE, S. W., \& PosNer, M. J. Processing of visual feedback in rapid movements. Journal of Exporimental Psy. chology, 1968, $77,155-158$.

chology, $1968,77,155-158$.
RABBIT, $P$. M. A. Error correction time without external RABBIT, $P$. M. A. Error correctionals.
signere, $1966,812,488$.

WELFORD, A.T. The psychological refractory period and the timing of hloh-speed performance-a review and a theory. British Journal of Psychology, 1952, 48, 2-19.

(Received February 10, 1969)

Journal of Experimental Psychology

1969, Vol. 82, No. 1, 187-189

\title{
EFFECTS THAT A MASSED REPETITION OF ONE PAIR HAS ON OTHER PAIRS IN A LIST ${ }^{1}$
}

\author{
GEORGE W. MCCONKIE 2
}

Department of Education, Cornell University

\begin{abstract}
It was hypothesized that a massed repetition of one word pair in a list facilitates the recall of other pairs in that list. This was confirmed using six-pair lists with Murdock-type tests of individual pairs in the lists. A massed repetition at Serial Positions 1, 3, or 4 resulted in better recall of the list as a whole, and there was a striking absence of peaks in the recall curves at points corresponding to the repeated pairs.
\end{abstract}

In the study of verbal learning, repeating information generally increases the likelihood that $S$ will recall it. Recently, a limitation to this law has been reported in studies which have found that when two presentations of the same item follow each other in immediate succession, the effect of the repetition may be greatly reduced or even eliminated entirely (Greeno, 1964). Theories proposed to account for this effect (Atkinson \& Shiffrin, 1968; Landauer \& Rubin, 1966) have assumed that less total learning occurs when repetitions are massed. An alternative hypothesis is that the massing of presentations of the same item results in changes in the rehearsal pattern for the list, so

1 The data in this experiment were reported in a paper presented at the meeting of the Eastern Psychological Association, Washington, D. C., April 1968.

a Requests for reprints should be sent to George $W$. McConkie, Department of Education, Cornell University, Ithaca, New York 14850. the extra time comes to benefit not the repeated item, but other members of the list. Specifically, it might be expected that $S$ s spend their time during the massed repetition of one pair in rehearsing previously presented pairs, thus strengthening them rather than the repeated pair.

The present study was designed to test whether a massed repetition of one word pair in a list raises the recall probabilities of other pairs in that list, as suggested previously. This was accomplished by presenting six-pair lists with a massed repetition of one of the pairs in some lists. Recall for all items in the list was tested with the method used by Murdock (1964).

Method.-Sixty lists of six word pairs each were constructed by randomly pairing common English words (frequency between 50 and 100 per million according to the Thorndike-Lorge, 1944, word 